\title{
DO COMBATE AO AEDES AEGYPTI E A LIBERDADE DO PROPRIETÁRIO AO DIREITO À SAÚDE
}

\author{
ON THE COMBAT OF THE "AEDES AEGYPTI" \\ AND THE OWNER'S RIGHT TO THE "RIGHT TO HEALTH"
}

Plauto Faraco de Azevedo(*)

\section{RESUMO}

O escrito busca solução para a dificuldade de combate à dengue, em face da tensão entre normas constitucionais protetoras da liberdade individual e do dever do Estado de garantir o direito à saúde. Considera os Direitos Fundamentais, de modo a superar o seu aparente antagonismo por meio do balancing process, ponderando interesses e bens juridicamente protegidos na situação concreta. Nesse sentido, também é examinada a legislação sanitária infraconstitucional.

\section{Palavras-chave}

Direito Sanitário, Direito Sanitário e combate à dengue, Direito Sanitário e balancing process.

\section{ABSTRACT}

This paper tries to solve the difficulty of erradicating the dengue (Aedes aegypti), in view of the tension between constitutional regulations protecting the individual freedom and the State's duty of granting the right to health. It considers the Fundamental Rights, so as to overcome this apparent antagonism, by means of the balancing process, considering interests and juridically protected properties in the concrete situation. In this sense, the infraconstitutional sanitary legislation is also examined.

(“) Doutor em Direito pela Universidade Católica de Louvain, Bélgica. Ex-Professor dos Cursos de Graduação e Pós-graduação stricto senensu da Faculdade de Direito da UFRGS. Professor Titular do Curso de Pós-graduação-mestrado ém Direito da Universidade Luterana do Brasil (ULBRA). 
Keywords

Sanitary Law, Sanitary Law and the fight against dengue (Aedes aegypti), Sanitary Law and the Fundamental Rights.

\section{DOS FATOS}

Tendo em vista a progressiva expansão da dengue, cuja forma hemorrágica é potencialmente letal, há uma determinação das autoridades sanitárias no sentido de articular ações capazes de conjurar esta situação, mediante a busca de criadouros do mosquito Aedes aegypti nas residências e propriedades particulares. Sem que se atinja eficazmente tal objetivo, poderá ocorrer uma epidemia dessa doença.

Disperso o mosquito em vários bairros de um determinado município, é indispensável que todos os imóveis nele situados sejam trabalhados pelos agentes de saúde, com a periodicidade máxima de sessenta dias. Sucede que há imóveis fechados no momento da visita sanitária e outros há em que o proprietário não a permite. Como resultado tem-se que, em municípios com infestação domiciliar significativa e em estações do ano propícias ao desenvolvimento do vetor, há um índice de pendência (casas fechadas e recusas) em torno de $20 \%$, o que pode ensejar a transmissão da dengue. Tal é a situação em Minas Gerais e no Rio de Janeiro. Neste último, há cerca de 550 mil imóveis não trabalhados a cada dois meses.

Pretendendo subsidiar a atuação dos agentes administrativos e operadores do direito, o Centro de Estudos e Pesquisas de Direito Sanitário da Universidade de São Paulo realizou, em 12.8.2002, uma oficina de trabalho, para a qual pudemos elaborar nossa contribuição.

\section{DOS FUNDAMENTOS TEÓRICOS DO TRABALHO}

A análise do problema demanda, previamente, a enunciação de seus pressupostos teóricos.

Partimos de uma concepção do direito capaz de visualizá-lo em suas múltiplas perspectivas - notadamente dogmáticas, estimativas e sociológicas - , de modo a apreender o quadro social e jurídico de forma abrangente, possibilitando a consideração do assunto em perspectiva multidisciplinar global, sem incorrer em cisões arbitrárias justificáveis apenas ideologicamente. (1)

(1) AZEVEDO, Plauto Faraco de. Crítica à dogmática e hermenêutica jurídica. Porto Alegre: Fabris, 1989. passim. Ideologia aqui tem o sentido assinalado por Marx, em sua Ideologia Alemã, escrita 
Desta maneira, não abstraímos os juízos valorativos indispensáveis à consideração da matéria. Tampouco isolamos os dados jurídicos dos dados políticos. Os primeiros constituem objeto da Ciência Jurídica, com método próprio, inseparável dos juizos de valor, ${ }^{(2)}$ interligados à política, entendida como escolha de meios e fins, no trato da coisa pública. Esta conjunção de todo natural era proclamada por Aristóteles, ao afirmar serem as leis "obras da arte política", sendo a política "a ciência suprema e arquitetônica por excelência", dispondo "sobre o que se deve fazer e sobre o que é preciso abster-se", englobando e subordinando, em razão de sua finalidade, todas as demais ciências. ${ }^{(3)}$

A dissociação dos dados jurídicos dos políticos veio a ser afirmada, com pretensões de cientificidade, com a ascensão da burguesia, por ocasião da Revolução Francesa. Coube-lhe "o mérito, não pequeno, de haver sido a primeira a compreender, inteiramente, o valor político do direito e a grande força de coesão que é capaz de proporcionar ao poder político".(4) A burguesia, cristalizando sua visão do mundo no Código de Napoleão, perde o ímpeto revolucionário. Abandona "o jusracionalismo racionalista como direito de insurreição", passando "a esposar a sua própria versão do sub lege libertas", que se exprime por meio de uma nova estruturação de forças sociais, configurada em um "código-paradigma da nova estrutura social". ${ }^{(5)}$ Só a lei passa a ter valor, sendo o Estado seu fundamento único. O método jurídico passa a ser o dedutivo, tanto na elaboração quanto na aplicação da lei. Ao sistema jurídico cerrado corresponde o processo hermenêutico fechado, sendo proibido ao juiz qualquer atividade criativa. Exprime-se esta posição na Escola da Exegese.

Incorporando sua visão política no sistema legal, estabelece-se, tanto do ponto de vista doutrinário quanto do jurisprudencial, a separação do direi-

entre 1845 e 1946: "Quase toda ideologia reduz-se, ou a uma concepção absurda desta história (história dos homens), ou a uma concepção que dela faz total abstração. A ideologia, ela própria, não é senão um dos aspectos desta história". Não é de estranhar que a ideologia tome o lugar da realidade, pois dispōe de meios materiais para isto... MARX, Karl. L'idéologia allemande (Conception matérialiste et critique du monde). In: Oeuvres. Éd. Établie, présentée et annotée par Maximilien Rubel. Paris: Gallimard, 1982. t. 3 (Philosophie) (Bibliothèque de la Pléiade), pp. 1037-1325, nota p. 1054, 1720, nota 1.

(2) Como escreve Larenz, "a ciência do Direito desenvolve por si métodos de um pensamento 'orientado a valores', que permitem complementar valorações previamente dadas, vertê-las e orientar a valoração que cada vez á exigida, pelo menos em determinados limites, a tais valorações previamente achadas. Nesta medida são as valorações suscetiveis de confirmação e passiveis de uma crítica racional", sem que os resultados obtidos possam "alcançar o mesmo grau de segurança e precisão de uma dedução matemática ou de uma medição empreendida de modo rigorosamente exacto. LARENZ, Karl. Metodologia da ciência do direito. $3^{\mathbf{2}}$ ed. Lisboa: Fundação Calouste Gulbenkian, 1997, p. 3.

(3) ARISTÓTELES. Ethique à Nicomaque. Nouv. trad. avec introd., notes et index par J. Tricot. $2^{a}$ ed. Paris: Librairie Philosophique J. Vrin, 1967. I, 1, 1094 a-b, pp. 34-5.

(4) GROSSI, Paolo. Absolutismo jurídico y drecho privado en el siglo XIX. Barcelona: Universidad Autónoma de Barcelona, 1991, pp. 12-14.

(5) LYRA FILHO, Roberto. Para um direito sem dogmas. Porto Alegre: Fabris, 1980, p. 22. 
to positivo da política. Vale dizer, a inarredável instância política, que preside a elaboração e aplicação do direito positivo, fica obscurecida pela impossibilidade de sua visualização "científica". Em conseqüência, a Ciência do Direito positivo afasta a consideração e o questionamento da origem e do fundamento das leis, entendendo ser suficiente a apreensão de seus aspectos formais. O jurista é "relegado à categoria de exegeta com a função meramente passiva". ${ }^{(6)}$

A questão da legitimidade das leis é banida da Ciência Jurídica que se instaura com o positivismo, tendo-se por suficiente a aferição de sua legalidade, isto é, basta à lei seguir os trâmites formais necessários à sua elaboração. A partir daí, o jurista deve contentar-se com juizos de constatação, alheios aos valores, tanto situados à base das leis quanto por elas buscados. Separa-se a ordem jurídica de seus fundamentos axiológicos, o que vai gerar, sob a ótica da aplicação do direito positivo, a indiferença pelos resultados sociais alcançados pelas leis. Ao jurista só interessa o trato da ordem jurídica positiva, de seu arranjo lógico-formal no sistema jurídico. Esta situação determinou a construção de discursos paralelos do jurista, do jusfilósofo, do sociólogo do direito e do historiador do direito, sem que houvesse comunicação entre essas falas, impossibilitando a aferição da dimensão ontológica do direito.

Tudo isso se explica em perspectiva histórica. Os revolucionários franceses tinham aversão à atuação dos Parlements, que haviam causado profundos problemas às reformas que a realeza desejou empreender, ao final do Ancien Régime. A elas se opondo e decidindo as questões jurídicas segundo os mais diversos critérios, jurídicos e não jurídicos, sua lembrança determinou que os revolucionários tratassem de restringir ao máximo o poder do judiciário, sendo-Ihe determinada a aplicação estrita da lei, de modo automático. (7) $\mathrm{Na}$ ordem constitucional francesa de 1791, "a primazia da lei conduz à preeminência do Legislativo e a expressão 'poder judiciário não é senão um artifício' tendo a Assembléia Constituinte Francesa por objetivo conceder o mínimo poder político aos juízes". ${ }^{(8)}$

O culto estrito da lei derivava, também, do avanço que a certeza, trazida pela codificação, propiciava ao tráfico jurídico, substituindo-se à legislação imprecisa, esparsa, derivada de múltiplas fontes, característica do Ancien Régime.

Volvidos mais de dois séculos de notável ação codificadora, a situação é bem outra. A atividade legislativa está longe de traduzir a "vontade geral". As leis são, freqüentemente, reflexos de interesses de grupos desin-

(6) GROSSI, Paolo, op. cit., pp. 12-4.

(7) VEDEL, Georges. Droit administratif. Paris: Presses Universitaires de France, 1958, t. 1, pp. 37-8.

(8) HALPERIN, Jean-Louis. "Introuvable pouvoir judiciaire. Le Monde de la Révolution Française", $n$.

10; Journal des droits de l'homme, Paris, out./1989, p. 21. 
teressados do bem comum. Há, ainda, as "leis motorizadas", na expressão de Legaz y Lacambra, ${ }^{\left({ }^{9}\right)}$ oriundas do Executivo, em nome de razões de Estado, hoje denominadas "imperativios econômicos", destinadas à proteção de poderosos grupos nacionais ou internacionais, em detrimento dos interesses da maioria das pessoas.

As leis multiplicam-se, gerando incertezas e antinomias, de cujos interstícios beneficiam-se os pescadores de águas turvas. Não há dúvida que a crise do direito, aspecto da crise civilizacional geral, esteja a demandar uma dogmática jurídica transpositivista, capaz de organizar e sistematizar as normas jurídicas no ordenamento legal, procedendo simultaneamente de forma analítico-descritiva e crítico-valorativa. Só assim é possível redescobrir o sentido do discurso jurídico, perdido no formalismo estéril em que mergulhou. Constitui este uma ideologia desfiguradora do real, em nome de uma cientificidade caracterizada pelo menosprezo da situação histórica presente. ${ }^{(10)}$

A dogmática jurídica há de ser ciente da politicidade do Direito e da dimensão política do Poder Judiciário, do que não deixa dúvida Dalmo de Abreu Dallari, em livro que veio a lume já como clássico do Direito. ${ }^{(11)}$ Não é possivel conformar-se com uma ciência jurídica desvitalizada, indiferente às contingências sociais e à legitimidade da ordem jurídica.

O que se vê, em toda periferia capitalista, é a exclusão social crescente, sem que os juristas, em sua grande maioria, atentem a esta trágica situação. Não pode o jurista assistir contemplativamente a um jogo político de cartas marcadas, de que derivam leis indiferentes ao bem comum ou ao bem de todos, enquanto se ocupa de sutilezas legais no trato formal da ordem jurídica.

Mais do que nunca tem-se de lembrar a observação de Dostoievski, notável conhecedor da natureza humana, ao escrever que "nenhum homem vive sem uma finalidade. Uma vez que a finalidade e a esperança desapareceram, a angústia transforma, freqüentemente, o homem em um monstro...".(12) A superação do caráter trágico do quadro histórico presente exige que se tenha em vista a politicidade do Direito.

Como aponta Hermann Heller, foi "na luta contra a arbitrariedade absolutista que se acreditou poder assegurar a legitimidade pela legalidade, de tal maneira que o povo vinha a ditar leis por si mesmo e o resto da atividade estatal devia submeter-se às mesmas". Mas "a divisão de poderes, de cará-

(9) LEGAZ y LACAMBRA, Luis. Filosofia del derecho. $4^{\circ}$ ed. Barcelona: Bosch, 1975, p. 378.

(10) AZEVEDO, Plauto Faraco de. Crítica à dogmática e hermenêutica jurídica, passim. "Juiz e direito rumo a uma hermenêutica material". Revista da Ajuris. Porto Alegre, 15 (43):13, jul. 88.

(11) DALLARI, Dalmo de Abreu. O poder dos juizes. São Paulo: Saraiva, 1996, passim.

(12) GIDE, André. Dostoïevski. Paris: Gallimard, 1964, p. 82. 
ter organizador, tem como fim garantir a segurança jurídica e é, por isto mesmo, um meio técnico simplesmente, que nada diz com respeito à justiça do direito...". Por isso, a legalidade do Estado de Direito não pode substituir a legitimidade. Todo poder estatal deve a sua conservação e formação à vontade humana, do que decorre que nele atuem "tanto as forças morais mais elevadas como uma imponente massa de estupidez e maldade, de infâmia e arbitrariedade".(13)

O internacionalista Celso $D$. de Albuquerque Mello, em texto bastante revelador e servido por excelente bibliografia, acentua que "o Direito seja ele qual for é cada vez mais político, mais utilizado pelo Poder visando à sua própria conservação". (14)

Tanto assim é que se pode observar, como é o caso brasileiro, que uma inadequada visão política dos problemas sociais conduz a opções insatisfatórias do ponto de vista legal. É assim que se trata de liberar o investidor externo do pagamento da CPMF, ao mesmo tempo que se sacrificam os investimentos sociais, por "falta de recursos".

\section{DA CONSTITUIÇÃO COMO SEDE DE TOPOI RENOVADORES DA ORDEM JURIDICA}

Apesar desta equivocada política, que resulta em um ordenamento jurídico muitas vezes confuso, o poder vê-se na contingência de acordar quando fatos graves assomam no horizonte. Nessa circunstância, o amparo vem de lugar menosprezado, atacado, diminuído. Este lugar é a Constituição da República, de 1988, com freqüência qualificada de "mastodôntica", "guia telefônico", "barroca" etc. Cumpre que se enfatize, ao contrário do que afirmam seus detratores, que se trata de documento político-jurídico notável, marcando ponto alto na evolução constitucional brasileira, embora, como é natural, perfectível. Nela se destacam a exemplar enumeração dos direitos e deveres individuais e coletivos (art. 5, I a LXXVII), não excludente de outros direitos e garantias decorrentes do regime, dos seus princípios constitucionais ou dos tratados internacionais em que a República seja parte. Pontos altos da Carta Política acham-se na enunciação dos direitos fundamentais sociais, dentre os quais se inclui a saúde (art. $6^{\circ}$ ), os direitos dos trabalhadores urbanos e rurais (arts. $7^{\circ}$ a 11 ), além da exemplar estruturação do Ministério Público, ao qual cabe a defesa da ordem jurídica, do regime democrático e dos interesses sociais e individuais indisponíveis (art. 127). Dentre as funções institucionais deste relevante Órgão, acha-se a obrigação de zelar

(13) HELLER, Hermann. Teoria do Estado. São Paulo: Mestre Jou, 1969, pp. 261, 265, 272.

(14) MELLO, Celso D. de Albuquerque. O direito internacional público em transformação. São Paulo: Resenha Universitária, 1976. 
pelos serviços de relevância pública, promovendo as medidas necessárias à sua garantia (art. 129, II). Quanto à ordem econômica, assina-Ihe a finalidade de assegurar a todos existência digna, conforme os ditames da justiça social (art. 170).

A saúde é tratada de modo próprio, com o relevo que lhe cabe, sendo considerada direito de todos e dever do Estado (art. 196). As ações e serviço de saúde são de relevância pública (art. 197). Ao Sistema Único de Saúde compete executar as ações de vigilância sanitária e epidemiológica (art. 200, II). O meio ambiente é objeto de um capítulo paradigmático, de notável clareza e abrangência (art. $225, \S \S 1^{\circ}$ a $6^{\circ}$ ), que se conecta com várias outras previsões constitucionais no mesmo sentido. Tanto basta para que se perceba o valor da Constituição, que necessita ser por todos defendida e tornada eficaz pela Administração, pela participação social e, notadamente, pelo Poder Judiciário. É preciso que haja, como proclama Hesse, vontade de constituição. ${ }^{(15)}$ Isto é tanto mais importante quanto maiores forem as pressões que desejam desfigurá-la e que a tem diminuído, em vários pontos.

\section{DA TRANSIÇÃO DO PARADIGMA CIENTÍFICO}

A Constituição de 1988, bem ao contrário do que afirmam seus inimigos, acha-se na linha moderna do constitucionalismo, seguindo valiosas vertentes doutrinárias.

Na medida em que estabelece como um dos fundamentos do Estado Democrático de Direito a dignidade da pessoa humana e como um dos objetivos fundamentais da República a promoção do bem-estar de todos, assinalando como um objetivo da ordem econômica assegurar a todos existência digna, alude, claramente, a opções valorativas fundamentais nela contidas. Assim fazendo, destoa do paradigma científico-jurídico dominante, que prima por pretender afastar dos limites do direito positivo as valorações que presidem a elaboração das leis e que, necessariamente, impregnam o processo hermenêutico precedente à sua aplicação.

Ademais, tais preocupações com valores atritam com as diretrizes neoliberais, alheias aos interesses comuns, que pretendem que o mercado a tudo proverá. Tem-se visto!

Este paradigma, que se acha no centro da crise civilizacional presente, consagra o positivismo jurídico gerador da "ideologia da separação", ${ }^{(16)}$ que

(15) HESSE, Konrad. A força normativa da constituição. Trad. de Gilmar Ferreira Mendes. Porto Alegre: Fabris, 1991, p. 32. Titulo original: Die Normative Kraft der Verfassung.

(16) LYRA FILHO, Roberto. Para um direito sem dogmas, cit., p. 11. 
muito dificulta o exercício da função transformadora do direito positivo, levando o jurista a limitar-se à função conservadora do status quo. ${ }^{(17)}$

\section{DOS DIREITOS FUNDAMENTAIS DE PRIMEIRA GERAÇÃO AO DIREITO SANITÁRIO — DA DESCONSTRUÇÃO NEOLIBERAL}

O modelo resiste, perturba o raciocínio jurídico, limita seu método, tolhe a criação responsável e inteligente do direito pelos tribunais, mas não consegue impedir que se abram brechas, através das quais vêm a luz e vicejam novas disciplinas jurídicas, cuja própria natureza evidencia um novo rumo no direito positivo, em que as valorações se tornam translúcidas e a interdisciplinaridade se impõe. Tal é o caso do Direito Ambiental e do Direito Sanitário.

Para a definição deste último, "tanto é necessária a discussão filosófica ou sociológica que permite afirmar a saúde como um direito (abarcando seus aspectos individuais, os coletivos e, igualmente, aqueles difusos, derivados do desenvolvimento social), como é indispensável que se dominem os instrumentos adjetivos que possibilitam a realização efetiva do direito à saúde".(18)

No preâmbulo da Constituição da Organização Mundial de Saúde OMS, de 1946, "é apresentado o conceito de saúde (então) adotado: 'saúde é o estado completo de bem-estar físico, mental e social e não apenas a ausência de doença"'. Dada a dificuldade de aceitação desse conceito, que diz corresponder "à definição de felicidade", outros conceitos têm sido propostos. Uma coisa, no entanto, é certa: "qualquer enunciado do conceito de saúde que ignore a necessidade de equilibrio interno do homem e deste com o ambiente, o deformará irremediavelmente".(19)

No Estado de Direito, que se consolida com a Revolução Francesa, é fundamental o princípio da legalidade sobre o qual se devem estruturar sua ação e, conseqüentemente, as medidas indispensáveis à implementação e à manutenção da saúde. Com o tempo, criou-se um sistema legal de proteção dos denominados direitos fundamentais de primeira geração, de forma geral definidos na Declaração dos Direitos do Homem e do Cidadão de 1789, posteriormente transformada em preâmbulo da Constituição Francesa de 1791.

(17) AZEVEDO, Plauto Faraco de. Limites e justificação do poder do Estado. Petrópolis: Vozes, 1979, pp. 15-23.

(18) DALLARI, Sueli Gandolfi. "Direito sanitário". In. ARANHA, Iório; TOJAL, Sebastião Botto de Barros (orgs.). Manual do Curso de Especialização a distância em Direito Sanitário para membros do Ministério Público e da Magistratura Federal. Brasília: UNB, 2002, pp. 47-72.

(19) Idem, ibidem. 
Embora se tenha dado um grande passo, estabelecendo-se a igualdade de todos perante a lei, a experiência histórica demonstrou a sua insuficiência. Com a sua enunciação e com o conjunto de direitos e liberdades então estabelecidos, a burguesia liberou-se dos grilhões feudais, possibilitando sua realização econômica e construindo-se a sua participação no processo político. Todavia, a grande massa do povo foi conduzida à miséria e ao desalento, como demonstra a história das normas de proteção ao trabalho que foram sendo progressivamente elaboradas, a partir do Moral and Health Act, de 1802, sob o governo de Robert Pill, na Inglaterra. A partir dessa fonte de inspiração, elaboraram-se normas análogas na Prússia, em outros Estados alemães e na França. Resultava claro "que o regime individualista e liberal não produzira a igualdade afiançada por seus defensores".(20)

É que "aos líderes revolucionários bastava que se declarassem extintos os privilégios e instituída a igualdade perante a lei, para que a burguesia vencedora fosse realmente livre. Isso porque os obstáculos, até então postos ao exercício da liberdade burguesa, decorriam dos privilégios outorgados à aristocracia e da insegurança dos direitos, que tinham como fonte única a vontade do soberano (por isso mesmo, dito absoluto) e não da falta de recursos materiais para tal exercício".(21)

Verificou-se que a igualdade formal perante a lei "não atendia ao anseio de liberdade real de todos aqueles que haviam sido excluídos do processo de elaboração legislativa". Foram excluídos tanto do direito de voto quanto do direito de representação política as mulheres e os homens que não tivessem renda superior a determinado valor. ${ }^{(22)}$

Começam, então, as lutas, até hoje inacabadas, pela efetiva participação política de todos os cidadãos válidos e pela emancipação econômica da classe trabalhadora. A influência da Revolução Russa, de 1917, a quebra da bolsa de Nova York de 1929, a Primeira e a Segunda Guerras Mundiais evidenciaram fissuras insanáveis no Estado Liberal, conduzindo ao Estado do Bem-Estar Social. Vale dizer, do Estado intervencionista, que passa a preocupar-se com a justiça distributiva, de cuja estruturação participam decisivamente os sindicatos, editando-se normas criadoras dos direitos sociais e protetoras do trabalho. O Estado do Bem-Estar Social foi, sem dúvida, até hoje, a melhor realização humana do ponto de vista político-jurídico.

Com a queda do Muro de Berlim e a desintegração da União Soviética, em 1989 e 1991, respectivamente, surge uma corrente do pensamento polí-

(20) DE LA CUEVA, Mario. Derecho mexicano del trabajo. 12 ed. Mexico: Porrúa, 1970, t. I, pp. 23-6.

(21) DALLARI, Sueli Gandolfi, op. cit.

(22) DALLARI, Sueli Gandolfi, op. cit. 
tico-econômico, a qual, revelando desprezo pelo direito e valendo-se do caráter unipolar do mundo atual, busca desconstruir o Estado do Bem-Estar Social. É o neoliberalismo que, apregoando a modernidade, quer voltar ao contexto do século XIX, desconstituindo os direitos fundamentais sociais. Assim se explicam boa parte dos ataques à Constituição "dinossáurica", de 1988. ${ }^{(23)}$ No arcabouço do Estado do Bem-Estar Social emergiram, ainda, os direitos fundamentais de solidariedade, dentre os quais se destacam 0 direito ao ambiente ecologicamente equilibrado, o direito à paz e o direito à saúde.

\section{DA COMPLEMENTARIDADE DOS DIREITOS FUNDAMENTAIS E DE SEU EVENTUAL ANTAGONISMO IN CASU — BALANCING PROCESS}

Isto posto, sendo o Estado Democrático de Direito um Estado modelado pelas leis, a Constituição de 1988 estabelece a inviolabilidade do direito à vida, à liberdade, à igualdade, à segurança e à propriedade, conforme especificado em seu art. $5^{\circ}$.

No caso vertente relativo à dengue, o direito à liberdade está intimamente ligado ao exercício do direito de propriedade, visto que proprietários há que se negam a colaborar com a ação sanitária de combate a esta doença, impedindo a visita dos agentes sanitários votados a debelá-la. Tal atitude impede que se efetue a proteção e defesa da saúde pública, pondo, sem qualquer dúvida, em perigo o bem comum ou bem de todos, que só se pode realizar mediante a ação eficaz das autoridades sanitárias.

Temos que o dilema se põe por duas razões: $1^{2}$ ) o caráter individualista da moderna proteção do direito à liberdade e à propriedade, forjados no Estado Liberal, o qual ainda se mantém em parte da doutrina, apesar de, ainda no século XIX, encontrarem-se várias decisões de tribunais franceses, apontando o abuso desse direito quando voltado a interesses meramente caprichosos ou egoísticos. ${ }^{(24)}$ Há uma sensivel dificuldade, no Ocidente, de assimilação do caráter social da propriedade e dos limites da liberdade quando exercitada contra o interesse comum, apesar de, no caso brasileiro, haver previsão constitucional inequivoca (arts. $5^{\circ}$, XXIII, 170, III e IV, e 186, II, da CF); $2^{a}$ ) o vício doutrinário do trato formal do direito positivo, conducente à desvalorização, senão ao esquecimento dos interesses pessoais e sociais à base das normas jurídicas.

(23) AZEVEDO, Plauto Faraco de. Direito, justiça social e neoliberalismo. São Paulo: Revista dos Tribunais, 1999, pp. 80-133.

(24) JOSSERAND, Louis. Del abuso de los derechos y otros ensayos. Trad. Carlos Valencia Estrada. Bogotá: Temis Libreria, 1982, pp. 7-8. 
Contra este vezo já investia, com proficiência, François Gény, em obra notável. O trabalho deste jurista buscou mostrar que a interpretação das fontes deveria se transformar em interpretação do Direito. Entendia ser necessário "buscar atrás do invólucro formal do texto legal a realidade, de que este não era senão o símbolo...". Era preciso, continuava ele, "alargar o horizonte dos juristas até a procura de uma justiça superior que permaneça humana por seu contato com as realidades do meio social...". Justiça esta que "paira muito acima dos modos de sua expressão contingente".(25) Não sendo as fontes "senão modos contingentes de expressão de uma realidade permanente", devem elas subordinar-se a esta realidade.

François Gény foi ainda mais explícito, a respeito dos interesses, no trato das questões jurídicas. Faz-se necessário à sua adequada solução o "reconhecimento de todos os interesses conflitantes em jogo, avaliandoIhes a respectiva força, pesando-os, por assim dizer na balança da justiça, a fim de fazer preponderar o mais importante deles, segundo um padrão social, e, afinal, estabelecer o equilíbrio entre eles, tão ardentemente desejável". (26)

Das duas razões supra-referidas decorre a tendência à absolutização tanto da liberdade quanto da propriedade. A "emergência, embora débil, tênue e obstaculizada, do indivíduo, no interior de um espaço antes reservado aos Estados soberanos", ${ }^{(27)}$ não pode conduzir a uma concepção absoluta de seus direitos.

Há alguns direitos "que valem em qualquer situação e para todos os homens indistintamente". Não são limitados nem diante de casos excepcionais. Deles constitui exemplo o direito de não ser escravizado e de não sofrer tortura - "esses direitos são privilegiados porque não são postos em concorrência com outros direitos, ainda que também fundamentais".

Na maioria dos casos, entretanto, pode ser necessária a escolha entre direitos fundamentais. "A dificuldade da escolha se resolve com a introdução dos limites à extensão de um dos dois direitos, de modo que seja em parte salvaguardado também o outro"... E isto é tanto mais importante quando se lembra "que, historicamente, a ilusão do fundamento absoluto de alguns direitos estabelecidos foi um obstáculo à introdução de novos direitos, total ou parcialmente incompatíveis com aqueles". E, aqui, o mestre italiano vem ao ponto que interessa ao tema em exame, escrevendo que "basta pensar nos empecilhos colocados ao progresso da legislação social pela teoria jusnatu-

(25) GÉNY, François. Science et technique en droit privé positif. Paris: Sirey, 1913, pp. 27-8.

(26) GÉNY, François. "Freedom of Judicial Decision", The Science of Legal Method, pp. 35-36. Cf. BODENHEIMER, Edgar. Ciência do Direito. Filosofia e metodologia jurídicas. Rio de Janeiro: Forense, 1966, p. 131, nota 26.

(27) BOBBIO, Norberto. A era dos direitos. Trad. Carlos Nelson Coutinho. Rio de Janeiro: Campus, 1992, p. 5. Título original: L'età dei diritti. 
ralista do fundamento absoluto da propriedade: a oposição quase secular contra a introdução dos direitos sociais foi feita em nome do fundamento absoluto dos direitos de liberdade. O fundamento absoluto não é apenas uma ilusão; em alguns casos é também pretexto para defender posições conservadoras". ${ }^{(28)}$

De nossa parte, temos insistido em que, na solução das questões jurídicas, há que se ter bem presentes os interesses e realidades humanas em questão. ${ }^{(29)} \mathrm{O}$ conceitos existem para a vida e não o contrário. ${ }^{(30)}$

A liberdade irrestrita conduz ao liberticídio. No caso, o não franquear a propriedade ao exame das autoridades sanitárias importa em seu exercício ilegítimo. Volta-se contra aquele que assim a exerce, contra a sua própria existência, de sua família e da sociedade.

Os direitos fundamentais interrelacionam-se mutuamente, sem que uns prevaleçam sobre os outros. Sucede que, em determinadas circunstâncias, uns devem limitar-se de modo a salvaguardar-se outros. É o que ocorre com a liberdade, quando confrontada com a necessidade de proteção e defesa da saúde pública. Só assim é possível dar eficácia aos preceitos constitucionais dos arts. 196, 197 e 200, II, da Constituição Federal. Sendo a saúde direito de todos e dever do Estado, sendo as ações e serviços a ela referentes de relevância pública e competindo ao Sistema Único de Saúde executar as ações de vigilância sanitária e epidemiológica, tais dispositivos só podem ser efetivados mediante a restrição à liberdade e à propriedade, nos limites indispensáveis à contenção da dengue.

Como ficou assentado, em 4.10.1991, em documento assinado por algumas das mais expressivas figuras do meio jurídico nacional, "a correta interpretação do art. 197 do texto constitucional implica o entendimento de ações e serviços de saúde como o conjunto de medidas dirigidas ao enfrentamento das doenças e suas seqüelas através da atenção médica e curativa, bem como de seus determinantes e condicionantes de ordem econômica e social".

As ações e serviços de saúde só podem, efetivamente, enfrentar a dengue, cuja gravidade e potencial epidemiológico mostram-se evidentes, atentando-se à sua relevância pública. Na situação presente, esta se impõe, diante da liberdade individual exercida em contraposição às suas ações. Chega-se a esta conclusão valorando-se todos os dados da situação concreta, vale dizer, aferindo-se o "peso" dos interesses em questão. Assim tem procedido

(28) Idem, ibidem, pp. 20-2. O grifo é nosso.

(29) AZEVEDO, Plauto Faraco de. Método e hermenéutica material no direito, passim.

(30) VON JHERING, Rudolf. L'esprit du droit romain. Trad. O. de Meulenaere. $3^{\mathbf{3}}$ ed. Paris: Lib. A. Maresq, 1886, v. 4, §69, p. 311. 
os tribunais alemães, assentando-se como princípio de decidir a validade, no caso, do interesse mais relevante e da proporcionalidade entre meios e fins, uma vez que "o meio escolhido não deve exceder uma medida racional. "A 'ponderação de bens' no caso concreto é um método de desenvolvimento do direito, pois que serve para solucionar colisões de normas - para as quais falta uma regra expressa na lei - , para delimitar umas das outras as esferas de aplicação das normas que se entrecruzam...". Assim, Larenz coloca com clareza o problema, ainda que precipuamente focalizando o direito privado. $^{(31)}$

Canotilho trata do assunto sob o título "Ponderação de Bens", de modo translúcido. Escreve que "as idéias de ponderação (Abwägungen) ou de balanceamento (Balancing) surgem em todo lado onde haja necessidade de 'encontrar o direito' para resolver 'casos de tensão' (Ossenbüh) entre bens juridicamente protegidos. O método de ponderação de interesses é conhecido há muito tempo pela ciência jurídica (...) Aqui nos interessará a ponderação no direito constitucional. ${ }^{(32)}$ Reconhece, pois, o mestre português que a idéia não é nova.

Aliás, parece-nos que o problema não se restringe aos princípios constitucionais ou àquelas normas constitucionais de "natureza tendencialmente principial'. (33) O problema é imanente à toda interpretação do direito, como já aludia Gény, uma vez que o processo hermenêutico supõe sempre valorizações de regras jurídicas e de fatos, considerando-se a potencial incidência daquelas sobre estes, num determinado contexto histórico-jurídico. A não valorização dos fatos e das leis conduz ao formalismo jurídico que, por sua vez, leva à incerteza jurídica, ao contrário do que comumente se afirma. ${ }^{(34)}$ A ponderação de bens é imanente tanto à elaboração do direito positivo quanto à sua aplicação. A ponderação de fatos e de bens ou de interesses, nos casos concretos, freqüentemente conduz à necessidade de escolha entre duas ou mais regras potencialmente aplicáveis às situações concretas. A pretensão de aplicação subjuntiva não é defensável, como 0 demonstra a moderna investigação hermenêutica. É evidente, por outro lado, que a ponderação é mais sensível e mais exigente de justificação no direito constitucional.

É necessário enfatizar que "a ponderação é um modelo de verificação e tipização da ordenação de bens em concreto". Não pode ser, de modo algum, um modelo de abertura para uma justiça 'casuística', 'impressionísti-

(31) LARENZ, Karl. Metodologia da ciência do direito. Trad. José Lamego. $3^{\text {an }}$ ed. Lisboa: Fundação Calouste Gulbenkian, 1997, pp. 574-87. Título original: Methodenlehre der Rechtswissenschaft.

(32) CANOTILHO, José Joaquim Gomes. Direito constitucional e teoria da constituição. $3^{2}$ ed. Coimbra: Livraria Almedina, 1998, p. 1161.

(33) CANOTILHO, José Joaquim Gomes, op. cit., p. 1165.

(34) AZEVEDO, Plauto Faraco de. Aplicação do direito e contexto social, passim. 
ca' ou de 'sentimentos'. Precisamente por isso é que o modelo de balancing não dispensa uma cuidadosa topografia do conflito nem uma justificação da solução do conflito através da ponderação. ${ }^{(35)}$

A topografia do conflito serve para "identificar o âmbito normativo dos bens em relação de tensão". Assim, o teste de razoabilidade permitirá "descobrir o desvalor constitucional de alguns interesses pretensamente invocados como dignos de proteção em conflito com outros". Por esta forma, sabese que não é razoável, por exemplo, "um direito fundado numa norma que estabelece a presunção do domicílio da mulher no domicílio do marido e será de todo desrazoável essa mesma presunção no caso de separação de facto". (36)

O sentido do balancing process não se encontra em "atribuir um significado normativo ao texto da norma, e sim em equilibrar e ordenar bens conflitantes (ou, pelo menos, em relação de tensão) num determinado caso. ${ }^{(37)}$

\section{REFERÊNCIA ÀS NORMAS VIGENTES TENDO EM VISTA EVENTUAL REQUERIMENTO DE LEGISLAÇÃO INFRACONSTITUCIONAL ESPECÍFICA PARA REALIZAÇÃO DO CONTROLE SANITÁRIO}

Consoante 0 art. 23, II, da Constituição Federal, a matéria relativa à saúde e assistência pública é de competência comum da União, dos Estados, do Distrito Federal e dos Municípios. Não poderia ser de outra forma, considerando-se a extensão e a relevância do campo de ação da polícia sanitária.

Mas, sendo assim, é da União a competência predominante "em assuntos de higiene e segurança pública, porque em nossos dias não há doença ou moléstia que se circunscreva unicamente a determinada região ou cidade", em face da rapidez e abundância dos meios de transporte que conduzem homens e produtos por todo o planeta. ${ }^{(38)}$

O controle sanitário, essencial à manutenção da saúde pública, pode ensejar dificuldades e despertar resistências de parte da mesma população em favor de quem é exercido. Como registra Ruy Cirne Lima, isto ocorreu quando da aplicação da Lei de Vacinação Obrigatória, que deu origem, em

(35) CANOTILHO, José Joaquim Gomes, op. cit., p. 1163.

(36) Idem, ibidem.

(37) Idem, ibidem, p. 1162.

(38) MEIRELLES, Hely Lopes. Direito administrativo brasileiro. $27^{\circ}$ ed. atualizada por Eurico de Andrade Azevedo, Délcio Balestero Aleixo, José Emmanuel Burle Filho. São Paulo: Malheiros, 2001, p. 139. 
14.11.1904, a um levante militar no Brasil. ${ }^{(39)}$ Considerando-se a experiência histórica, há que se buscar prudente eficácia no combate à dengue.

O exame da legislação sanitária vigente demonstra a existência de normas jurídicas apropriadamente elaboradas, sem que, no entanto, se encontrem normas específicas incidentes sobre a hipótese fática em exame.

O Código Sanitário do Estado de São Paulo — Lei n. 10.083, de 23.9.1998, prevê medidas, em caso de epidemias, em seu Livro V, nos arts. 507 a 511. No art. 510, lê-se que "na iminência ou vigência de epidemia de maior gravidade (...) serão tomadas medidas particularmente rigorosas para impedir a disseminação da moléstia", podendo "abranger a limitação parcial ou total do direito de locomoção". Dispõe o art. 511 que "esgotados os meios de persuasão, a autoridade sanitária requisitará o auxílio da autoridade policial local ou regional para execução de medidas referentes à profilaxia de doenças".

A Lei Federal n. 8.080, de 19.9.1990, que dispõe sobre as condições para a promoção, proteção e recuperação da saúde, estabelece, em seu art. $6^{\circ}$, que estão incluídas no campo de atuação do Sistema Único de Saúde SUS: I - a execução de ações: a) de vigilância sanitária; b) de vigilância epidemiológica, acrescendo que a vigilância sanitária compreende "problemas sanitários decorrentes do meio ambiente" (art. 6으 $\S 1^{\circ}$ ). Em seu $\S 1^{\circ}$, diz o que se entende por vigilância sanitária e, em seu $\S 2^{\circ}$, o que significa vigilância epidemiológica. Em seu art. $9^{9}$, I, dispõe que "a direção do Sistema Único de Saúde - SUS, é única (...)", sendo exercida pelo Ministério da Saúde, no âmbito da União; no âmbito dos Estados e do Distrito Federal, pela Secretaria de Saúde ou órgão equivalente; no âmbito dos Municípios, pela respectiva Secretaria de Saúde ou órgão equivalente. $O$ art. 16 esclarece que à direção nacional do SUS compete a vigilância epidemiológica e sanitária assim como a coordenação de participação na execução de ações de vigilância epidemiológica (art. 16, I, $c, d$, e VI). No parágrafo único deste artigo, está expresso que "a União poderá executar ações de vigilância epidemiológica e sanitária em circunstâncias especiais, como na ocorrência de agravos inusitados à saúde, que possam escapar do controle da direção estadual do Sistema Único de Saúde - SUS ou que representem riscos de disseminação nacional".

A Lei Federal n. 9.782, de 26.1.1999, define o Sistema Nacional de Vigilância Sanitária e cria a respectiva Agência, sob a forma de autarquia de regime especial, vinculado ao Ministério da Saúde, com atuação em todo o território nacional (art. $3^{\circ}$ ). $O \S 6^{\circ}$ do seu art. $8^{\circ}$ enuncia que "o Ministro da

(39) CIRNE LIMA, Ruy. Princípios de direito administrativo. Porto Alegre: Sulina, 1964, p. 118. 
Saúde poderá determinar a realização de ações previstas nas competências da Agência Nacional de Vigilância Sanitária, em casos específicos e que impliquem riscos à saúde da população".

Por fim, o art. 29, desta mesma lei, enfatiza os princípios fundamentais da atividade administrativa a pautarem as ações da Agência Nacional de Vigilância Sanitária: legalidade, celeridade, finalidade, razoabilidade, impessoalidade, imparcialidade, publicidade, moralidade e economia processual.

Sendo "a saúde direito de todos e dever do Estado" (art. 196 da CF) e sendo as respectivas "ações e serviços" de relevância pública (art. 197 da CF) e competindo ao Sistema Único de Saúde "executar as ações de vigilância sanitária e epidemiológica" (art. 200, II, CF), não se pode conceber a necessidade de realização deste direito sem que o sistema jurídico forneça os meios indispensáveis para tal, ainda mais quando a competência, na matéria, é comum da União, dos Estados, do Distrito Federal e dos Municípios (arts. 23, II, e 24, XII, da CF). Segundo velha parêmia jurídica, quem determina os fins há de conceder os meios para sua realização.

Tratando-se de problema abrangente de mais de uma unidade federativa, impõe-se a urgente atuação das autoridades sanitárias da União, sinalizando rumos para a ação coadjuvante dos Estados e Municípios.

Fica claro que, dentro desses princípios, compete à Agência Nacional de Vigilância Sanitária tomar as medidas necessárias ao combate da dengue, podendo o Ministro de Estado da Saúde determinar a realização das respectivas ações, quando a situação implique risco à saúde da população, como é o caso.

Tendo em vista o exposto, inclinamo-nos pelo requerimento urgente de legislação infraconstitucional específica para o combate de epidemias, até porque, a permanecer o modelo político-econômico vigente, que pouco permite investir na área social, outras epidemias poderão surgir.

Tal requerimento, em nosso entender, deve partir da limitação da liberdade em face da necessidade de proteção e defesa da saúde pública, conforme supra-exposto. A partir da solução deste dado, entendemos que a legislação infraconstitucional deverá inspirar-se no ordenamento administrativo-sanitário vigente - Código Sanitário do Estado de São Paulo e legislação federal examinada, suscetível de ser sistematizada, tudo, obviamente, em conformidade com as normas constitucionais.

Sublinhe-se que os atos administrativos sanitários deverão ater-se à proporcionalidade necessária entre a ação e os fins visados. A mesma autoridade sanitária, auxiliada pela força pública, que execute atos necessá- 
rios à entrada em prédios particulares, deverá velar para que tais atos não excedam os limites da razoabilidade para a consecução dos fins visados. A propriedade tem de ser salvaguardada, exceto no indispensável à ação sanitária.

Aspecto prático delicado é o da apresentação dos fiscais sanitários, cuja identidade há de revestir-se da maior evidência, para que a eventual recusa do proprietário não se possa fundar em suspeita freqüentemente defensável, dada a situação social de violência reinante.

A pronta elaboração legal infraconstitucional deverá revestir-se de prudência e razoabilidade, de modo a oferecer solução ao problema da dengue e a outras situações epidêmicas análogas. 